\title{
Mountain waves can impact wind power generation
}

\author{
Caroline Draxl ${ }^{1}$, Rochelle P. Worsnop ${ }^{2,5}$, Geng Xia ${ }^{1}$, Yelena Pichugina ${ }^{2,5}$, Duli Chand ${ }^{3}$, \\ Julie K. Lundquist ${ }^{1,4}$, Justin Sharp ${ }^{6}$, Garrett Wedam ${ }^{7,8}$, James M. Wilczak ${ }^{5}$, and Larry K. Berg ${ }^{3}$ \\ ${ }^{1}$ National Renewable Energy Laboratory, Golden, CO 80401, USA \\ ${ }^{2}$ Cooperative Institute for Research in the Environmental Sciences, \\ University of Colorado Boulder, Boulder, CO 80309, USA \\ ${ }^{3}$ Pacific Northwest National Laboratory, Richland, WA 99352, USA \\ ${ }^{4}$ Department of Atmospheric and Oceanic Sciences, University of Colorado Boulder, Boulder, CO 80302, USA \\ ${ }^{5}$ Earth System Research Laboratory, National Oceanic and Atmospheric Administration, \\ Boulder, CO 80305, USA \\ ${ }^{6}$ Sharply Focused, LLC, Portland, OR 97232, USA \\ ${ }^{7}$ Avangrid Renewables, Portland, OR 97209, USA \\ ${ }^{8}$ Natural Power, Seattle, WA 98121, USA \\ Correspondence: Caroline Draxl (caroline.draxl@ nrel.gov)
}

Received: 29 April 2020 - Discussion started: 25 May 2020

Revised: 27 October 2020 - Accepted: 5 November 2020 - Published: 7 January 2021

\begin{abstract}
Mountains can modify the weather downstream of the terrain. In particular, when stably stratified air ascends a mountain barrier, buoyancy perturbations develop. These perturbations can trigger mountain waves downstream of the mountains that can reach deep into the atmospheric boundary layer where wind turbines operate. Several such cases of mountain waves occurred during the Second Wind Forecast Improvement Project (WFIP2) in the Columbia River basin in the lee of the Cascade Range bounding the states of Washington and Oregon in the Pacific Northwest of the United States. Signals from the mountain waves appear in boundary layer sodar and lidar observations as well as in nacelle wind speeds and power observations from wind plants. Weather Research and Forecasting (WRF) model simulations also produce mountain waves and are compared to satellite, lidar, and sodar observations. Simulated mountain wave wavelengths and wave propagation speeds (group velocities) are analyzed using the fast Fourier transform. We found that not all mountain waves exhibit the same speed and conclude that the speed of propagation, magnitudes of wind speeds, or wavelengths are important parameters for forecasters to recognize the risk for mountain waves and associated large drops or surges in power. When analyzing wind farm power output and nacelle wind speeds, we found that even small oscillations in wind speed caused by mountain waves can induce oscillations between full-rated power of a wind farm and half of the power output, depending on the position of the mountain wave's crests and troughs. For the wind plant analyzed in this paper, mountain-wave-induced fluctuations translate to approximately $11 \%$ of the total wind farm output being influenced by mountain waves. Oscillations in measured wind speeds agree well with WRF simulations in timing and magnitude. We conclude that mountain waves can impact wind turbine and wind farm power output and, therefore, should be considered in complex terrain when designing, building, and forecasting for wind farms.
\end{abstract}




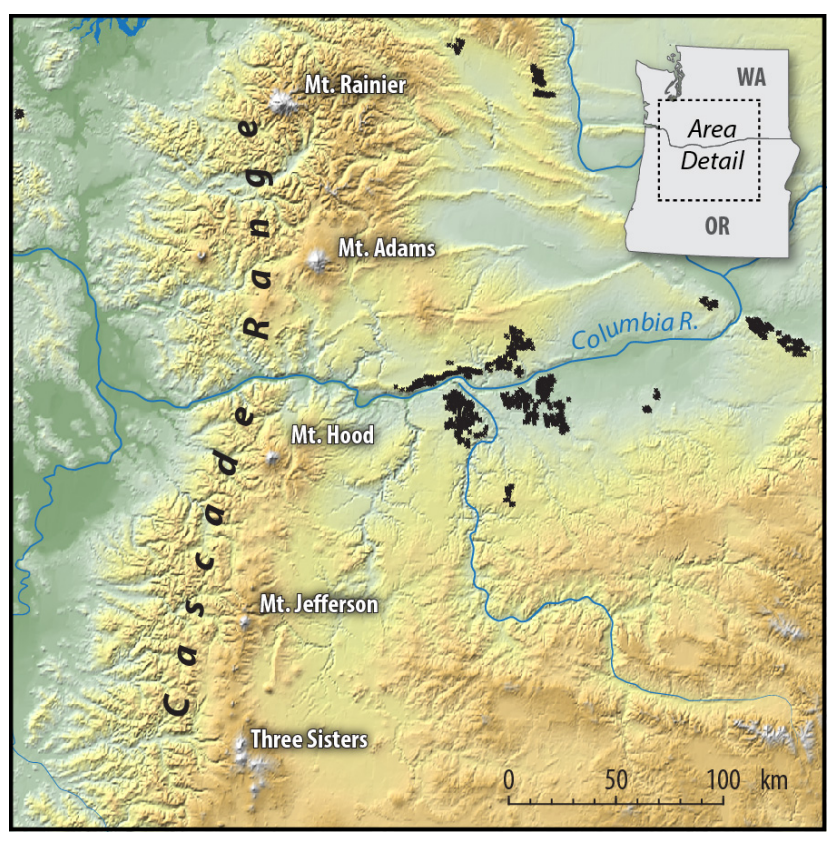

Figure 1. Map with the location of the major volcanoes (white labels) and wind farms (black dots) in the area. Figure by Billy Roberts, National Renewable Energy Laboratory.

\section{Introduction}

As wind farm deployment in the United States and worldwide continues to increase, contributions from renewable wind energy production to the electrical-generation portfolio are also increasing (AWEA Data Services, 2017; Global Wind Energy Council, 2018). The U.S. Department of Energy's (DOE's) Wind Vision study (U.S. Department of Energy, 2020) mapped out a target scenario for wind energy to provide $35 \%$ of the United States' electricity demands by 2050. Wind plants are already and will continue to be deployed in areas of complex terrain to satisfy that portfolio. Complex terrain, herein defined as terrain with irregular topography (e.g., mountains, valleys, coastlines, and canyons), can modify the flow within and far downstream of the terrain.

One area of complex terrain where numerous wind farms are deployed is the Columbia River basin in the northwestern United States, which is located east of the Cascade Range. The Cascade Range extends from southern British Columbia through Washington and Oregon to northern California, for $1100 \mathrm{~km}$ (Wikipedia, 2020), with a width of $130 \mathrm{~km}$. Volcanic summits in the area reach up to approximately $4000 \mathrm{~m}$ above mean sea level. During westerly flow, the Cascade Range poses an obstacle that impacts the weather and modifies the wind flow to the east of the Cascade Range, which impacts wind farm production of the deployed wind power plants in the area (Fig. 1).

During westerly winds with stable atmospheric conditions, air ascends the Cascade Range, and strong buoyancy per- turbations can develop in the form of mountain waves, or lee waves, downstream of the Cascade Range. The area is prone to these conditions primarily during the cold and transition seasons, mostly during spring. Mountain waves may be nearly stationary, propagating downwind, vertically propagating, or trapped. Vertically propagating waves are relevant to wind energy to the extent that they can lead to downslope windstorms. Trapped lee waves are relevant to wind energy because they occur in the lowest $1-5 \mathrm{~km}$ of the troposphere (American Meteorological Society glossary; Durran, 1990). With their horizontal wavelengths between 5 and $35 \mathrm{~km}$, trapped lee waves have anecdotally been recognized to impact wind farm production in the area, particularly if stationary.

The mountains of the Cascade Range can also block atmospheric flow and create a wake behind them. Mountain wakes are usually accompanied by significant drag and deceleration of low-level flow (Wells et al., 2008). During westerly winds, such mountain wakes are relevant for wind energy in the Columbia River basin, as they create meandering bands of low wind speeds that can extend hundreds of kilometers downwind and decrease power output from wind farms. Their exact timing and location are hard to predict as they meander.

Mountain waves and wakes can and commonly do occur concurrently within the Columbia River basin (Wilczak et al., 2019; Pichugina et al., 2020). In this region, mountain wakes mostly occur downstream from Mt. Hood and Mt. Adams (Fig. 1), as seen from satellite observations and model simulations (examples are shown in Figs. 4 and 7). Both mountain waves and wakes impact wind plants and their power output. Because these phenomena can occur simultaneously and under the same conditions, distinguishing their relative impacts can be challenging. Taking advantage of the rich dataset of the Second Wind Forecast Improvement Project (WFIP2; Shaw et al., 2019; Wilczak et al., 2019) and mesoscale simulations from the Weather Research and Forecasting (WRF) model, this paper focuses on one phenomenon only - the impact of mountain waves on wind farms. Many studies have analyzed mountain wakes over the last decades (e.g., Lindsay, 1962; Bourgeault et al., 2001; Klemp and Lilly, 1978; Doyle and Durran, 2002; Durran, 2003; Smith, 2004; Smith and Broad, 2003; Grubišić and Billings, 2007; Smith et al., 2007; Mahalov et al., 2011; Nappo, 2012; Vosper et al., 2012; Miglietta et al., 2013; Durran, 2015; Fritts, 2015). However, even though one article (Rasheed et al., 2014) mentions that mountain waves result in horizontal and vertical wind shear, which can significantly impact wind power production, none quantified that impact. Therefore, it is our goal to document for the wind energy community, in particular for forecasters and the wind energy industry, the importance of considering mountain waves in operations and wind plant deployment. A second goal of this paper is to analyze to what degree the mesoscale WRF model is able to capture mountain wave 
characteristics in the complex terrain of the Columbia River basin, a key region for wind energy production.

This paper is structured as follows: in the next section, we describe the measurements and model simulations used. We then identify and quantify mountain waves in Sect. 3 from a meteorological perspective and as simulated by WRF, before we analyze the impact of mountain waves on wind farm output using nacelle winds and supervisory control and data acquisition (SCADA) data. In Sect. 4, we provide a discussion relating our findings to practical aspects of mountain waves in forecasting and operations then conclude in Sect. 5 with recommendations for actions during mountain wave events.

\section{Data and methods}

Our analysis is based on the extensive measurement network from WFIP2 (Shaw et al., 2019; Wilczak et al., 2019). WFIP2 is a program funded by the DOE and National Oceanic and Atmospheric Administration (NOAA) aimed at improving the accuracy of numerical-weather-prediction (NWP) model forecasts of wind speed in complex terrain for wind energy applications (Wilczak et al., 2019; Banta et al., 2020; Bianco et al., 2019; Olson et al., 2019; Pichugina et al., 2019, 2020). Measurements were collected during an 18-month field campaign between October 2015 and March 2017 in the Columbia River Gorge and the Columbia River basin (Fig. 1). For this paper, measurements from remote sensing instruments are used (Sect. 2.1) to identify mountain waves through time series analysis, spectra, and statistics. Satellite images (Sect. 2.2) further help identify mountain waves, and WRF model simulations (Sect. 2.3) support our analysis. Nacelle wind speeds and power output from a wind farm in the area portray the influence of mountain waves on wind plants.

\subsection{WFIP2 observations}

To analyze wind flow variability during mountain wave events, we use profile measurements from lidars and sodars (Sect. 2.1.1 and 2.1.2) that were deployed in the WFIP2 research area. These instruments continuously operated during the 18-month experiment, providing real-time data. These quality-controlled data are openly available to the public through the Data Archive and Portal (DAP; https://a2e. energy.gov/data, last access: 5 January 2021). Proprietary nacelle wind speeds from a wind farm in the area, as well as its power output (Sect. 2.1.3), quantify the impact of mountain waves on wind farms.

\subsubsection{Lidar data}

Several profiling and scanning lidars were deployed as part of the WFIP2 field campaign. This study uses measurements from the scanning Doppler lidar and the wind profiling lidar at the Wasco site (Fig. 2). The WindCube profiling li-
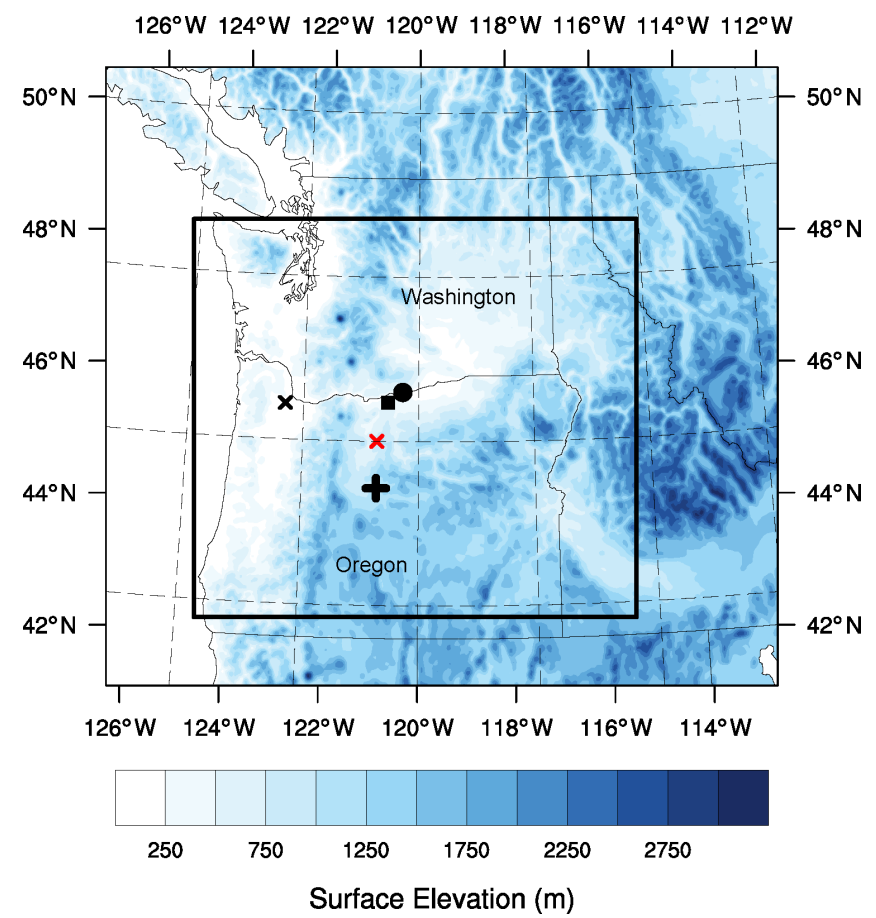

Figure 2. WRF modeling domains. The rectangle denotes the area of the $750 \mathrm{~m}$ domain. US state boundaries are indicated. The black $\mathrm{x}$ denotes the location of Troutdale; the cross denotes Prineville; the square denotes Wasco and Van Gilder Road; the circle denotes the location of the wind farm in the area; and the red $\mathrm{x}$ denotes the location in the WRF domain where profiles are plotted in Fig. 5. The Columbia River cuts through the Cascade Range at the border between the state of Oregon to the south and Washington to the north.

dars sample line-of-sight velocities sequentially in four cardinal directions along a nominally $28^{\circ}$ azimuth vertically and a nominal temporal resolution of $1 \mathrm{~Hz}$ (Aitken et al., 2012; Rhodes and Lundquist, 2013), simultaneously sampling 10 range gates centered at 40, 60, 80, 100, 120, 140, 160, 180, 200, and $220 \mathrm{~m}$ a.g.l. These lidars provide estimates of wind speed, wind direction, and vertical velocity within the surface layer and boundary layer up to $250 \mathrm{~m}$ a.g.l. (Bodini et al., 2019) that were also used for the selection of mountain wave cases. Basic quality control, requiring that an individual line-of-sight (LOS) velocity be measured with a carrier-to-noise ratio (CNR) greater than $-22 \mathrm{~dB}$, has been applied to these data. The 2 min averages are based only on the $1 \mathrm{~Hz}$ LOS with CNR exceeding $-22 \mathrm{~dB}$. Lidars require a sufficient number of scatterers for a return signal so that clean air conditions have lower availability (Aitken et al., 2012). 


\subsubsection{Sodar data}

In this paper we use sodar measurements from the Wasco and Van Gilder Road sites. At Wasco, the ART (Atmospheric Research \& Technology) VT-1 sodar model was deployed, which is a monostatic phased-array Doppler sonic detection and ranging (sodar) system. It provides a "virtual tower" for obtaining remote measurements of the wind profile up to a height of approximately $300 \mathrm{~m}$ at a vertical resolution of $10 \mathrm{~m}$. The system includes a 48-element acoustical array. At Van Gilder Road, which is close to Wasco, a triton wind profiler is used. This profiler measures wind speed, direction, and turbulence intensity at heights from 30 to $200 \mathrm{~m}$ above ground every $10 \mathrm{~min}$. The quality-controlled sodar data are stored on the DAP. Information about setup and filtering for the Wasco and Van Gilder Road sodars can be found in Atmosphere to Electrons (2017a) and Atmosphere to Electrons (2017b), respectively.

\subsubsection{Nacelle winds and turbine power output}

We use data from approximately 100 wind turbines from a wind farm in the WFIP2 region to assess how mountain waves influence observed wind speed and power output. The wind farm is located north of the Columbia River Gorge and experienced mountain wave events during the WFIP2 field campaign. From the turbine nacelles, we use $80 \mathrm{~m}, 10 \mathrm{~min}$ averaged wind speed data and 10 min averaged power output. Data from a single turbine, as well as spatially aggregated winds across an entire wind plant, are compared with outputs from corresponding WRF simulations (see Sect. 3.2).

\subsection{Satellite images}

The mountain waves are detected using visible clouds features from the satellite observations. We utilized both polarorbiting and geostationary satellite observations to locate the mountain waves downwind of mountain peaks. The cloud features are retrieved from the Geostationary Operational Environmental Satellite (GOES-14) routine observation over the continental United States. To have the best cloud contrast and spatial separation, we used $1 \mathrm{~km}$ resolution pixels from band 1 (approximately $630 \mathrm{~nm}$ ) of the GOES-14 satellite. The GOES-retrieved mountain wave features in the form of clouds are compared with Moderate Resolution Imaging Spectroradiometer (MODIS) satellite observations for better understanding. The comparison in both satellites looks reasonable, though the MODIS observations show finer cloud features due to higher spatial resolution $(0.25 \mathrm{~km})$. Since MODIS observations have higher spatial resolution but limited temporal resolution (only one MODIS satellite per day passes over the Columbia River basin), considering the temporal evaluation of waves, we decided to use the GOES-14 observations at a temporal resolution of $30 \mathrm{~min}$.

\subsection{WRF simulations}

Model simulations at 5 min resolution produced with the WRF model version 3.7.1 augment the observational analysis. We use model output from an inner domain with a $750 \mathrm{~m}$ grid spacing that was nested within a larger domain at $3 \mathrm{~km}$ grid spacing (Fig. 2). ERA-Interim reanalysis data (Dee et al., 2011) provide initial and boundary conditions. We used the Mellor-Yamada-Nakanishi-Niino level 2.5 boundary layer and surface layer schemes (Nakanishi and Niino, 2009), as they were improved upon within WFIP2; the Morrison double-moment microphysics scheme; the Rapid Radiative Transfer Model for Global Circulation Models; simple diffusion; and vertical velocity damping (Skamarock et al., 2008). This model setup has been successfully used in DOE's Mesoscale to Microscale Coupling project and was constructed with input from modeling experts in the project (e.g., Haupt et al., 2017).

Computations were carried out using 88 vertical levels, up to $10000 \mathrm{hPa}$, which were spaced approximately $5 \mathrm{~m}$ apart in the lowest $20 \mathrm{~m}$, with the grid spacing increasing continuously beyond that. This allows for a vertical resolution of $8-10 \mathrm{~m}$ within the turbine rotor layer (approximately 20 $150 \mathrm{~m}$ a.g.l.).

\section{Results}

Each week throughout the WFIP2 field program, scientists and wind energy forecasters reviewed the daily weather in the region and wrote a brief synopsis in an event $\log$ (Wilzcak et al., 2019) assessing the significance of the key phenomena (Pichugina et al., 2020) that impacted wind power generation. Key phenomena were categorized by having a "high", "medium", and "low" importance (\%) for wind energy (WE), which was estimated by analyzing all available observations, Bonneville Power Administration (BPA) power generation and schedule errors, power ramps, and the performance of NOAA's High-Resolution Rapid Refresh model (Fig. 3a). From this event $\log$, we found $95 \mathrm{~d}$ during the 18 months (548 d) where mountain wave activity was indicated by a meteorologist so that mountain waves were present at least $17 \%$ of the time. Each of the key phenomena were categorized further by three levels of significance (potential, interesting or relevant, or not currently of interest). The significance of mountain wave cases for each level of importance relative to all phenomena is shown in Fig. 3a.

As noted in the introduction, topographic wakes often occur simultaneously with mountain waves. During WFIP2, topographic wakes were recorded in the event $\log 15 \%$ of the time, based on analysis of wind speed observations, comparisons of observations in waked versus nonwaked areas, and their appearance in satellite images and horizontal slices of simulated wind speeds. Distributions of mountain waves and topographic wakes (Fig. 3b) show a high frequency of both events during spring months. 

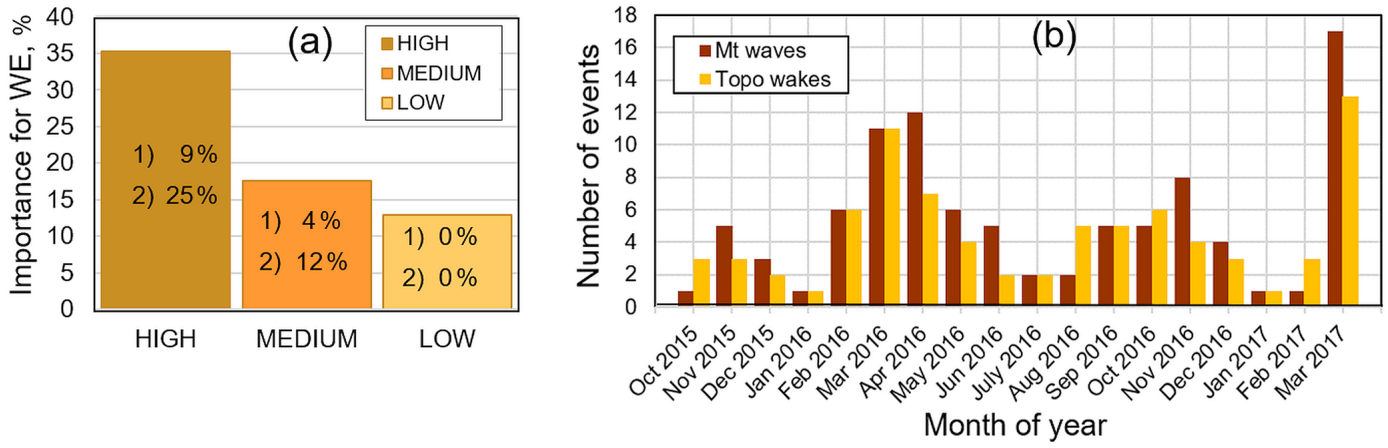

Figure 3. (a) Distribution of days during WFIP2 that exhibited observed phenomena that were ranked as of high, medium, and low importance to wind energy according to the event log. The frequency of cases per level of importance that are considered a potential (1) or interesting or relevant (2) case for wind energy is given in each bar. (b) Distribution of mountain waves and topographic wakes observed during WFIP2 according to the event log.

Scanning this event log as well as lidar and sodar observations, we identified $2 \mathrm{~d}$ where mountain waves had a strong presence over the area and impacted wind farms in the Columbia River basin. The first day (11 November 2016) is documented in Wilczak et al. (2019). In this paper, we focus on the second day (24 September 2016) because of the availability of measurements and SCADA data and the presence of typical characteristics of mountain waves.

\subsection{Analysis of model simulations on 24 September 2016}

Reichmann (1978) and Mastaler and Renno (2005) state that the best conditions for mountain waves are (i) the presence of a stable air mass, (ii) wind speeds aloft necessarily being greater than about $8 \mathrm{~m} \mathrm{~s}^{-1}$ at ridge level, (iii) the wind direction being nearly constant throughout the stable layer, (iv) the wind speed being constant or increasing with altitude, and (v) the wind direction being within $30^{\circ}$ of normal to the perturbing ridge. From these conditions it is deduced that the Scorer parameter (Scorer, 1949), an indicator for mountain wave development, should decrease with altitude. On 24 September 2016, all the above conditions were met in the model simulations, as will be discussed in this section.

On 24 September 2016, stationary mountain waves east of the Cascade Range were caused by flow from northwesterly directions. That flow, in turn, was forced by a low-pressure system over the western half of the continental United States (see Appendix). The area of the Columbia River basin was covered by clouds at 00:00 UTC, which completely dissolved by 07:30 UTC (not shown).

Mountain waves can be seen in the simulated horizontal wind field at $100 \mathrm{~m}$ a.g.l. (Fig. 4a) as relatively thin and similarly spaced oscillating strips of high and low wind speeds oriented approximately perpendicular to the wind direction. They are triggered by the flow over the Cascade Range already around 23 September 2016, at 16:00 UTC, and between 20:00 and 22:00 UTC they take over the whole area, impacting Prineville and a wind farm in the WFIP2 region. An elongated wake extending downstream from Mt. Hood (large triangle in Fig. 4a) is narrowed to a meandering band when the wakes cover the area. Wakes are also discernible downstream from Mt. Jefferson, the Three Sisters, and Broken Top.

A cross section of the simulated horizontal wind field, potential temperature, and the PBL (planetary boundary layer) top from west to east on 24 September 2016, at 04:00 UTC, centered over a wind farm (Fig. 4b), further shows the appearance of mountain waves in the simulations, up to approximately $4.5 \mathrm{~km}$ above sea level, as do oscillating patterns in the vertical wind speeds (Fig. 4c).

The stratification of the atmosphere during the occurrence of mountain waves is shown for Troutdale, a location west (and therefore upstream) of the Cascade Range, and for a location in the center of the area where waves occur (Figs. 2 and 5). The atmosphere is stably stratified, except from 00:00 to 03:00 UTC, where a well-mixed layer exists below the approximately $1500 \mathrm{~m}$ crest height up to approximately $1 \mathrm{~km}$. The simulated wind speed profiles show winds between approximately 6 and $10 \mathrm{~m} \mathrm{~s}^{-1}$ up to approximately $2.5 \mathrm{~km}$, decreasing, with a high wind shear, above $2 \mathrm{~km}$. In the center of the domain, during the time where mountain waves are present, the wind speeds are higher than at Troutdale but exhibit a similar wind shear above approximately $3 \mathrm{~km}$. The stable stratification, wind speed magnitudes (satisfying the constraint from Mastaler and Renno (2005) that wind speeds aloft must be greater than about $8 \mathrm{~m} \mathrm{~s}^{-1}$ at ridge level), constant wind speeds below $2 \mathrm{~km}$, and increased wind speeds above that are favorable conditions for the development of mountain waves.

Mountain waves are possible when the nondimensional mountain height is in the order of 1 (Mastaler and Renno, 2005). Therefore, we calculated the nondimensional mountain height and the Scorer parameter (Fig. 6) from the WRF simulations at Troutdale. The nondimensional moun- 


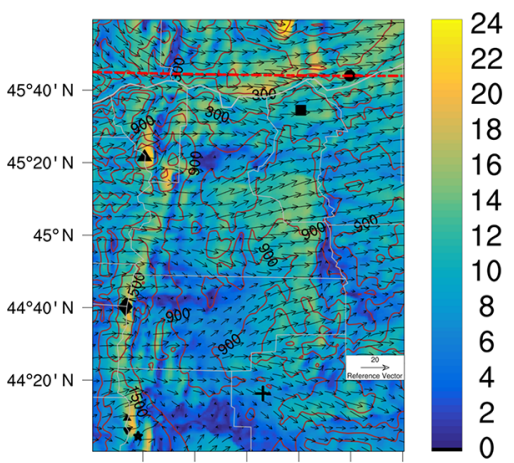

(a)

$121^{\circ} 20^{\prime} \mathrm{W} \quad 120^{\circ} 40^{\prime} \mathrm{W} \quad 120^{\circ} \mathrm{W}$

24
22
20
18
16
14
12 章
10
8
6
4
2
0

(b)
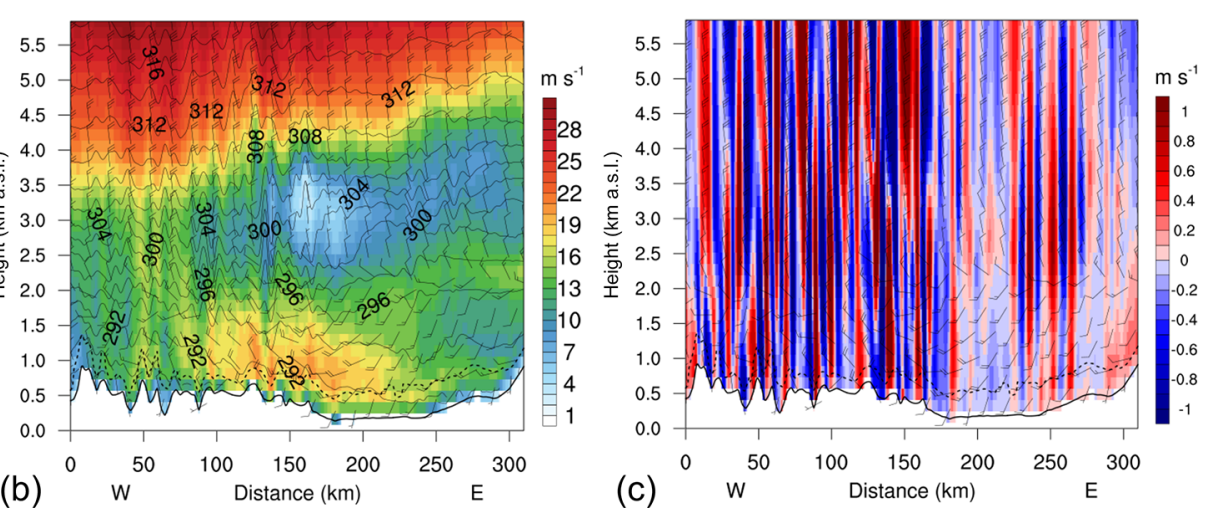

Figure 4. (a) Simulated wind field at $100 \mathrm{~m}$ a.g.l. The big triangle, diamond, cross, square, and circle denote the locations of Mt. Hood, Mt. Jefferson, Prineville, the Wasco instrument site, and the wind farm, respectively. The Three Sisters and Broken Top located in lower-left corner are shown by smaller triangles and a star, respectively. Contours show terrain elevation every $300 \mathrm{~m}$. The red dashed line indicates the transect along which cross sections in (b) and (c) are taken. Note that the cross sections in (b) and (c) extend beyond the bounds of this plot. (b) Cross section of horizontal wind speed from west to east through the wind farm. Wind speeds are color-shaded; lines denote potential temperature $[\mathrm{K}]$; the boundary layer top is dashed. (c) Cross section of vertical wind speeds through the wind farm at 04:00 UTC on 24 September 2016.
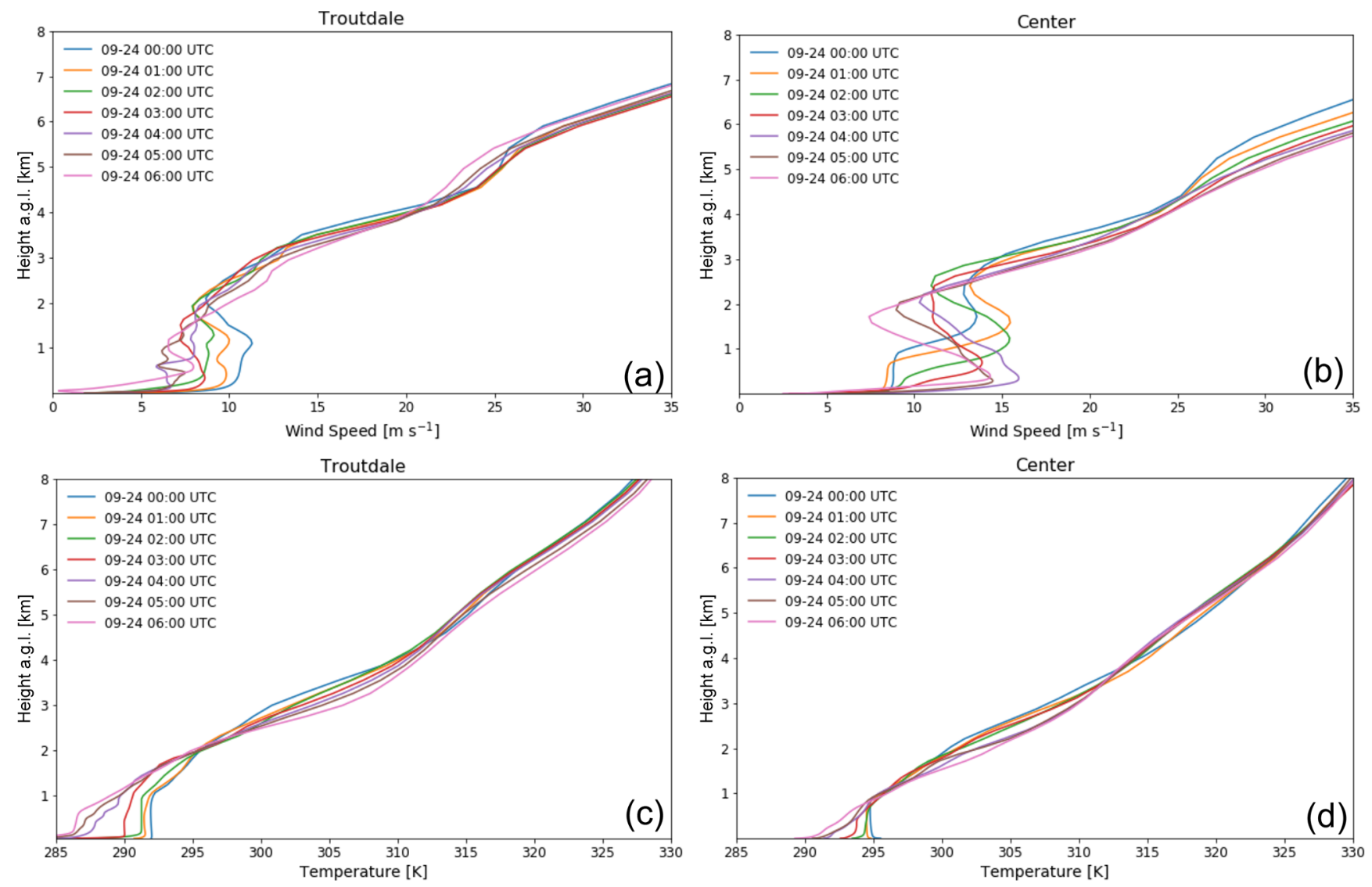

Figure 5. Simulated WRF wind speed $(\mathbf{a}, \mathbf{b})$ and potential-temperature profiles $(\mathbf{c}, \mathbf{d})$ at Troutdale $(\mathbf{a}, \mathbf{c})$ and a location in the center of the modeling domain, east of the Cascade Range, $(\mathbf{b}, \mathbf{d})$ during mountain wave activities. Please note that the date format in this figure is month day (mm-dd). 

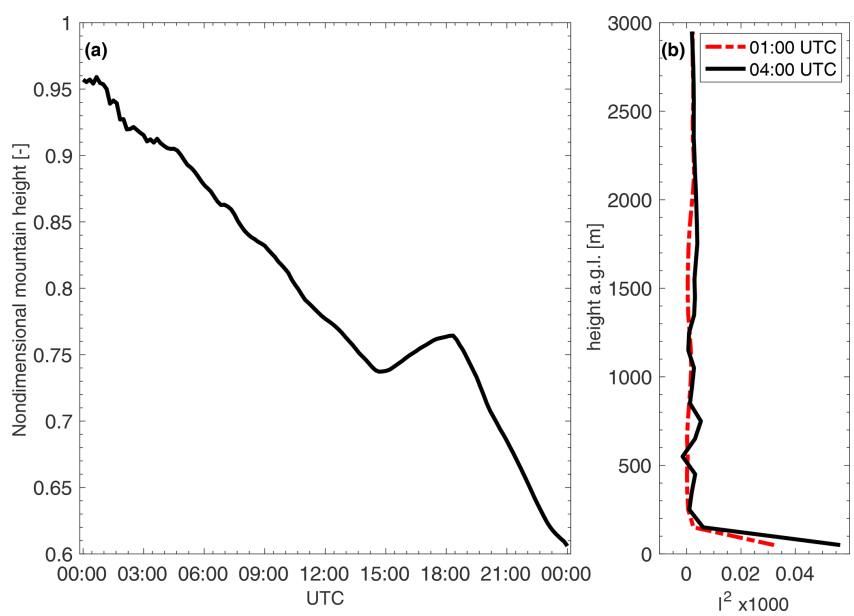

Figure 6. (a) Nondimensional mountain height as a function of time of day (UTC). (b) Scorer parameter at 01:00 UTC (dashed red) and at 04:00 UTC (solid) from model simulations.

tain height was calculated using the bulk method by Reinecke and Durran (2008), using an average free-stream velocity between 1500 and $7000 \mathrm{~m}$, a mountain height of $1500 \mathrm{~m}$, and a Brunt-Väisälä frequency between 0 and $7000 \mathrm{~m}$. Mountain waves are possible because the nondimensional mountain height was high during the entire day (Fig. 6). In fact, the horizontal wind field shows waves until approximately 15:00 UTC.

The Scorer parameter (Eq. 1) is a further measure to determine whether mountain waves develop:

$l^{2}=\frac{N^{2}}{U^{2}}-\frac{1}{U} \frac{d^{2} U}{d z^{2}}$

where $U(z)$ is the speed of the basic-state flow and $N(z)$ is the Brunt-Väisälä frequency, with $z$ being the vertical coordinate (Durran, 2003). According to Scorer (1949), waves are possible if atmospheric stability decreases or wind speed increases with height (Lindsay, 1962). In our case, wind speeds increase with height (Fig. 5). Moreover, when the Scorer parameter is nearly constant with height, conditions are favorable for vertically propagating mountain waves. Trapped lee waves can be expected when the Scorer parameter $l$ decreases with height. Figure $6 \mathrm{~b}$ shows that the Scorer parameter from model output at Troutdale at 01:00 UTC increases with height up to $\sim 200 \mathrm{~m}$ and is mostly constant above that. At 04:00 UTC, it also increases with height up to $\sim 200 \mathrm{~m}$, exhibits multiple maxima until about $1100 \mathrm{~m}$, and is nearly constant with height above that. Multiple maxima indicate that multiple wave systems may occur simultaneously. The slight change of the profile in time indicates that the simulated mountain waves may change their propagation characteristics slightly over time.
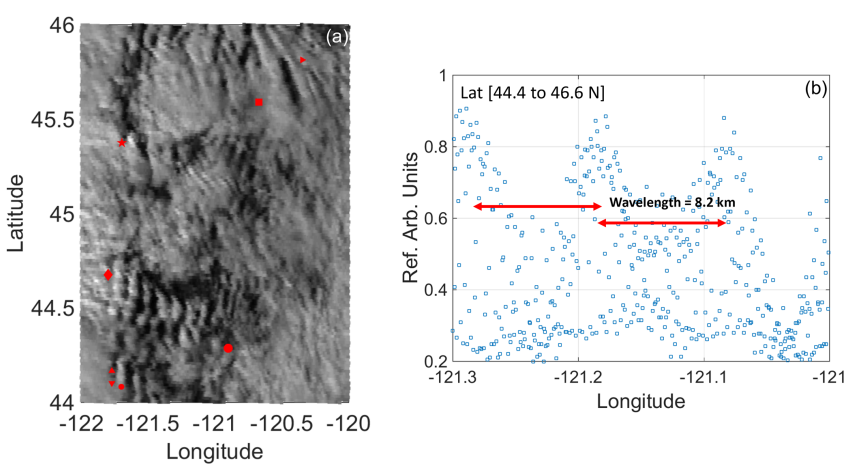

Figure 7. (a) GOES-14 satellite image on 23 September 2016, at 22:00 UTC. The red dots represent the same locations as in Fig. 4. (b) The dots denote cloud reflectance in arbitrary units (counts or normalized data) covering latitude 44.4 to $46.6^{\circ} \mathrm{N}$ at 22:00 UTC.

\subsection{Comparison of model simulations with observations on 24 September 2016}

We will now compare the model simulations with observations to see how well the model captures mountain waves. We will look at satellite images and lidar and sodar observations at Wasco (Fig. 2). Note that lidar and sodar observations represent data collected at a single point in space; therefore, signals in these data will indicate nonstationary mountain waves.

\subsubsection{GOES satellite imagery}

GOES visible reflectances at $1000 \mathrm{~m}$ resolution and $630 \mathrm{~nm}$ wavelengths (Fig. 7a) show a wavy cloud pattern similar to the simulated wind field in Fig. 4a on 23 September 2016, from 19:30 UTC until sunset (shown for 22:00 UTC on 23 September 2016). After sunset, visible satellite images cannot reveal any signals. The appearance of mountain waves during that time matches with the model simulations in which mountain waves appeared starting on 23 September 2016, around 16:00 UTC. From the clouds, a wavelength of approximately $8 \mathrm{~km}$ was deduced (Fig. 7a and b). The wavelength is calculated by averaging the cloud reflectance from 44.4 to $46.6^{\circ} \mathrm{N}$ along 121 to $121.3^{\circ} \mathrm{W}$, shown by the meridional distribution in Fig. 7b. Note the spatial heterogeneity in the cloud field (Fig. 7a), which indicates similar variability in the manifestation of mountain waves.

\subsubsection{Lidar and sodar observations}

Observations at fixed locations (such as from lidar or sodar) can reveal the presence of trapped lee waves through temporal fluctuations in the lee-wave pattern (Bougeault et al., 2001; Wilczak et al., 2019). Periods of alternating high and low wind speeds were observed at Wasco from all collocated remote sensing instruments as well as in the simulated horizontal wind field (Fig. 8). Good agreement is found between 


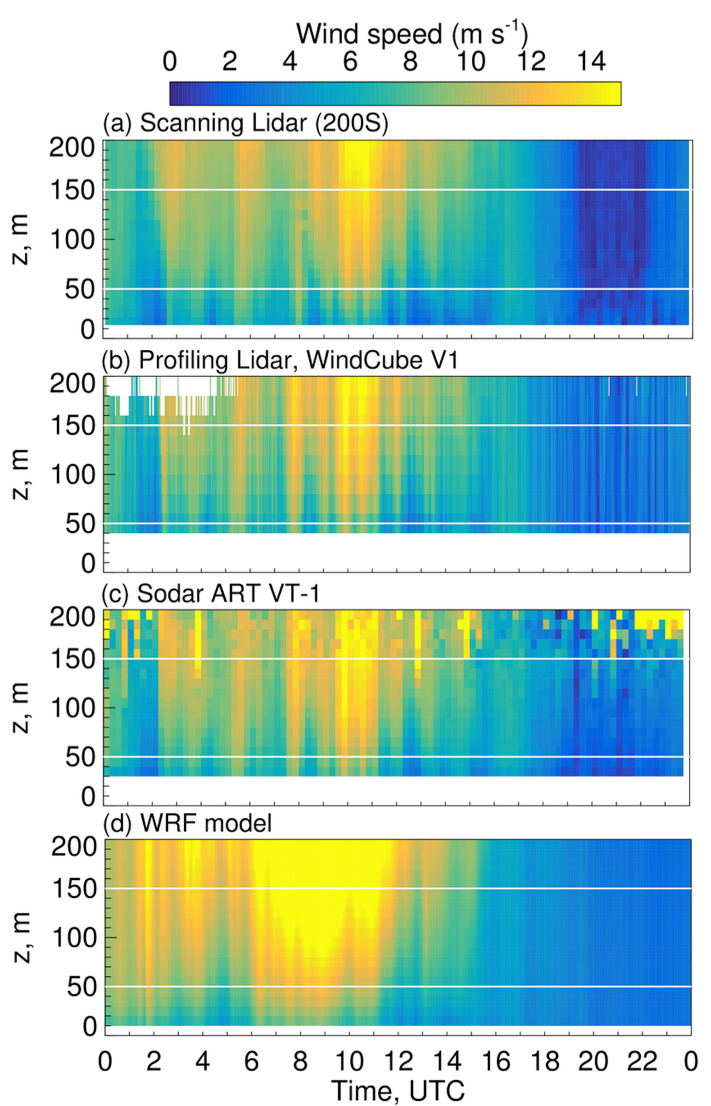

Figure 8. Observed wind speeds up to $200 \mathrm{~m}$ above ground as a function of time from the (a) scanning Doppler lidar (200S), (b) the profiling lidar (Wind Cube, V1), (c) the sodar (ART VT1), and (d) simulated wind speeds at Wasco on 24 September 2016. Two horizontal white lines in each panel indicate the $50-150 \mathrm{~m}$ layer where turbines operate.

data from all instruments (Fig. 8a-c), as waves manifest in all instruments starting near 02:00 UTC, increasing in amplitude until a maximum near 10:00 UTC, then decreasing. Clear patterns of waves are discernible in both measured and simulated wind speeds. However, during the high-wind-speed periods, WRF overpredicted the wind speed from 06:00 to 09:00 UTC. Further, the phase of the waves in WRF did not always match that of the observations. In general, the waves are well captured in time and magnitude.

\subsubsection{Wavelengths and speed of wave propagation observed on 24 September 2016}

From an operational-forecasting perspective, knowing when mountain waves will influence wind power and for which period of time can be valuable for forecasting for power trading and forecasting the balancing requirements in the power system - from both a regulatory and economic perspective. Nearly stationary mountain waves lend to less short-term volatility in energy production but potentially a still large de- viation from scheduled production, and they therefore create large balancing requirements for the duration of the event. Such stationary events can lead to large and costly imbalances for power producers. Large wavelengths ( $>18 \mathrm{~km}$ ) can exacerbate the imbalance for both grid operators and power producers by reducing (or enhancing) production over multiple wind farms at once, whereas shorter wavelengths (where several wavelengths occur within one wind production region) will tend to have some areas of enhanced production and other areas of reduced production, resulting in a beneficial netting effect. Quickly propagating mountain waves produce the netting effect on a temporal scale so that while short-term imbalances can be large and require costly balancing reserves, longer-term imbalances may be small. Balancing costs at all described timescales are important to grid operators and energy producers, but they require different planning. We therefore investigate whether our model simulations are able to forecast the speed of the mountain wave propagation, as well as their wavelengths.

From the spatial pattern of mountain waves in the $100 \mathrm{~m}$ wind speeds, we extract wind speeds along a latitude of $45.6^{\circ} \mathrm{N}$ and calculate the power spectrum using the fast Fourier transform (FFT) (Fig. 9). The spatial pattern of the waves at 50 and $200 \mathrm{~m}$ is similar (not shown). At this latitude, most of the WFIP2 sodar sites are located. Evidently, most of the power variances are explained by low-frequency waves and large wave patterns (Fig. 9b). For wavelengths shorter than $8 \mathrm{~km}$ the associated power variance is negligible. From the analysis in Sect. 3.2, we identified that mountain wave wavelengths range from 8 to $18 \mathrm{~km}$. In that range, the bulk of the power variance occurs between 23 September, at 22:00 UTC, and 24 September, at 04:00 UTC. Therefore, we reconstruct the wind field by filtering it with respect to wavelengths between 8 and $18 \mathrm{~km}$.

To confirm our choice of wavelength range, we show Hovmöller diagrams of the original and reconstructed hub-height wind speed (Fig. 10) at the targeted latitude. There is a mountain wave event particularly distinguishable between 23 September, at 22:00 UTC, and 24 September, at 04:00 UTC (Fig. 10a and power variance in Fig. 9b), which is well captured by the reconstructed wave pattern (Fig. 10b). To determine the wave period, Fig. 10c shows the power spectrum of the reconstructed (8-18 km wavelength) and observed hubheight wind speed. We have removed the low-frequency wave signals ( 24 and $12 \mathrm{~h}$ ) from both the observed and simulated time series to focus on high-frequency waves. We chose the wave periods to be between 1 and $4 \mathrm{~h}$ because that is within the time range of our interest (22:00 to 04:00 UTC) and it explains the majority of the power variance by the simulated mountain waves (Fig. 9b).

Finally, we reconstruct the simulated wind field at each time step using band-pass filtering (FFT), wavelength, and wave period constraints (Xia et al., 2020) and compare that with the observations (Fig. 11). Because the mountain wave event that we are interested in is particularly visible in the 

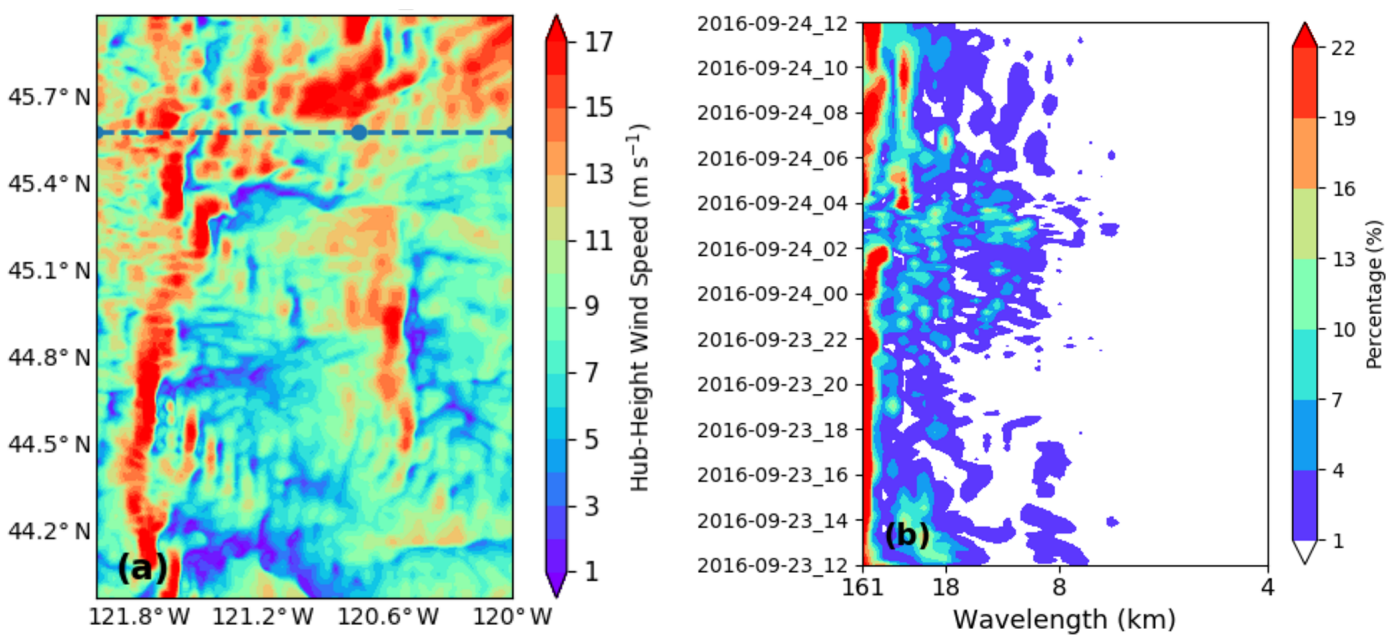

Figure 9. (a) Simulated horizontal wind speeds $\left[\mathrm{m} \mathrm{s}^{-1}\right.$ ] at $100 \mathrm{~m}$ on 24 September 2016, at 02:00 UTC; the dashed line at $45.6^{\circ} \mathrm{N}$ indicates where the FFT was taken. The dotted point represents the location of the sodar site at Van Gilder Road close to Wasco. (b) Hovmöller diagram of power variance with respect to wavelength at the targeted latitude. Please note that the date format in this figure is year month day (yyyy-mm-dd).
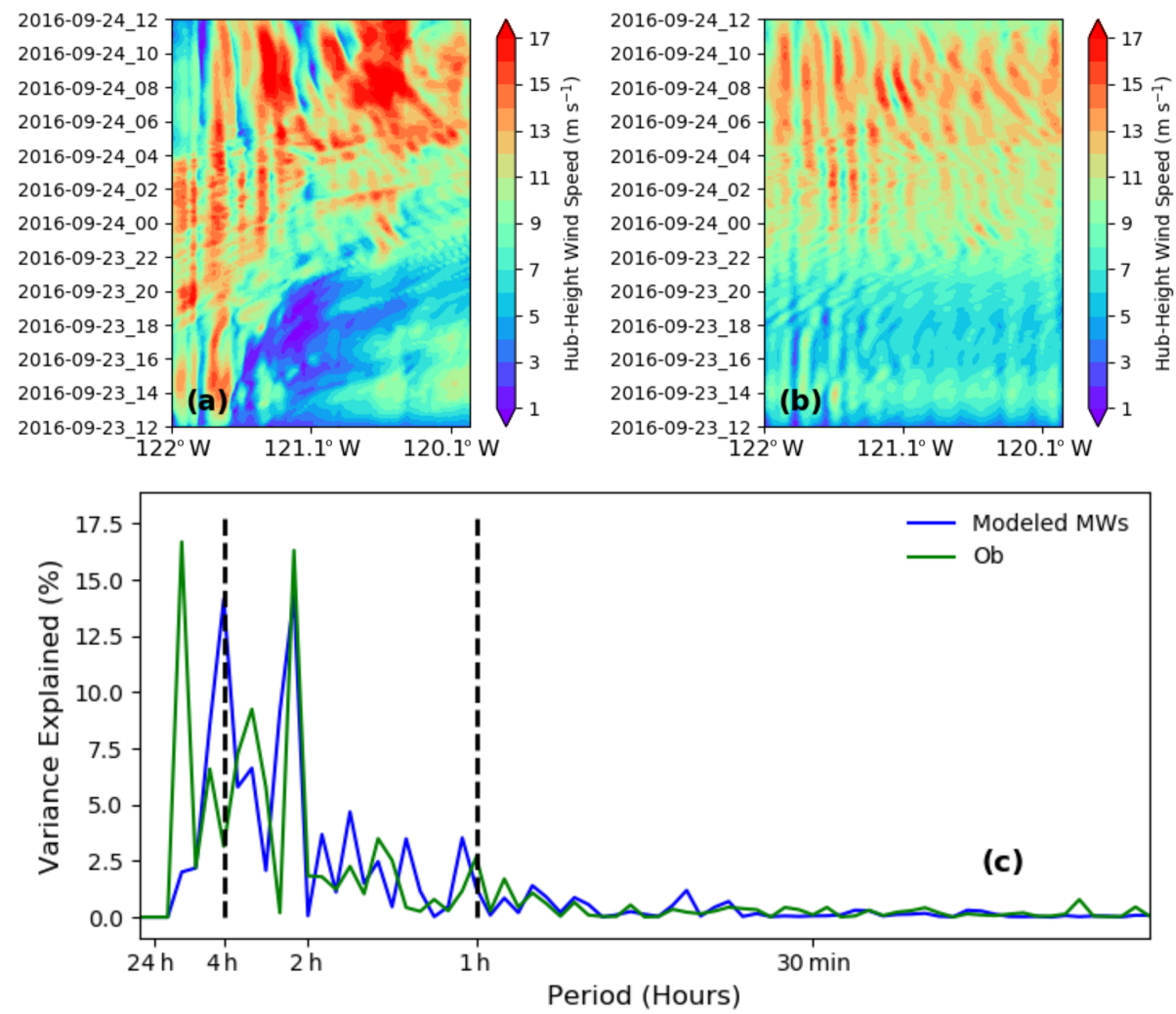

Figure 10. (a) Hovmöller diagram of simulated hub-height wind speeds at the targeted latitude. (b) Same as (a) but showing the filtered wind speeds with wavelengths from 8 to $18 \mathrm{~km}$. (c) Observed (green) and reconstructed (blue) power spectrum on the time domain for 24 September 2016. The simulated FFT was reconstructed with wavelengths from 8 to $18 \mathrm{~km}$. The dashed lines indicate the wave period of interest from 1 to $4 \mathrm{~h}$. Please note that the date format in this figure is year month day (yyyy-mm-dd). 


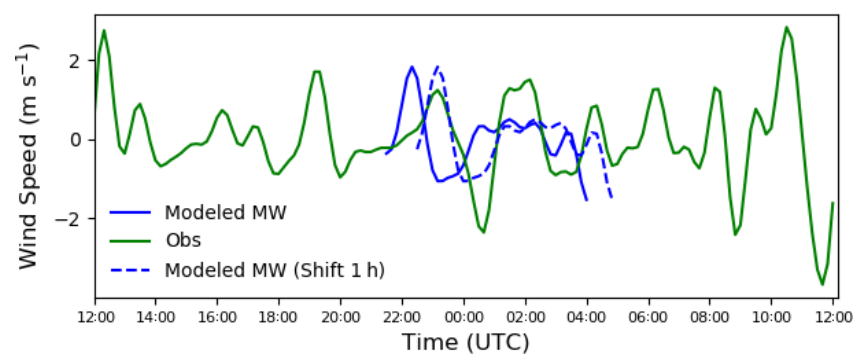

Figure 11. Observed (green) and reconstructed (blue) simulated $100 \mathrm{~m}$ wind speed time series from 23 September 2016, at 12:00 UTC, until 24 September 2016, at 12:00 UTC. The simulated wind speeds were reconstructed with wavelengths from 8 to $18 \mathrm{~km}$, and periods were from 1 to $4 \mathrm{~h}$, while the observed winds were reconstructed with periods from 1 to $4 \mathrm{~h}$. The simulated mountain waves were plotted from 22:00 to 04:00 UTC because the mountain wave event that we are interested in is particularly visible at that time. The dashed time series indicates the simulated mountain waves that were shifted by $1 \mathrm{~h}$.

simulations between 22:00 and 04:00 UTC the next day, we only plot that period for comparison. The reconstructed wind speed time series shows a $1 \mathrm{~h}$ shift compared to the observations. In addition, we can deduce a wave period of $2.5 \mathrm{~h}$; with a wavelength of $8-18 \mathrm{~km}$, we estimate the wave speed to be $1.5 \mathrm{~m} \mathrm{~s}^{-1}$. The results seem to be sensitive to the chosen grid point and the period of interest (not shown). For instance, we performed a similar analysis using a grid point that is about $7 \mathrm{~km}$ (10 grid points) away from the original one. The simulated wind field looks similar to that of Fig. 11, but the resemblance with the observations is weaker.

\subsection{Impact of mountain waves on power output}

The impact of mountain waves on wind power plant output in the Pacific Northwest has been anecdotally recognized by wind energy meteorologists for about a decade, and operational meteorologists know to expect additional power generation volatility when mountain waves are present. The first time this impact was documented in a peer-reviewed journal was in Wilczak et al. (2019). Wilczak et al. (2019) confirmed signals in wind plant power output through spectra by showing that the frequency range of dominant energy is consistent with the period of mountain waves identified via satellite and wind speed observations. In this paper, we provide additional proof of the impact of mountain waves on power output by analyzing wind farm power output from another wind farm in the area on a different day. We use nacelle wind speeds and model wind speeds as well as individual turbine and total farm power output.

First, power output from a wind plant in the study area is compared to measured wind speeds at the turbines and WRF output. Figure 12 shows the direct influence that mountain waves can have on power output of a single turbine. The number of wave crests (approximately six) agrees well with the lidar and sodar observations in Fig. 8. During the time when mountain waves were present (00:00-12:00 UTC), the winds were fairly strong (approximately $10 \mathrm{~m} \mathrm{~s}^{-1}$ ). Oscillations in measured wind speeds were around $5 \mathrm{~m} \mathrm{~s}^{-1}$ and agree well with WRF simulations in timing and magnitude. These oscillations in wind speed correspond with oscillations in observed turbine power. During this particular event, these oscillations are at such a critical point (region 2) in the power curve that small oscillations about the overall mean flow can make all the difference between full-rated power (approximately $2.3 \mathrm{MW}$ ) or $1 \mathrm{MW}$ of power at any given time.

Mountain waves can influence the total wind farm power output as well. The time series in Fig. 13 shows oscillations in total power output from the entire wind farm (green) and total power output from two other wind farms in the area (orange and blue). Oscillations of approximately $25 \mathrm{MW}$ exist in averaged power at the wind plant (shown in Fig. 15 as percentage) and did not get canceled out by alternating wave influences at different locations in the wind farm. Averaged wind speeds for that wind farm indicate similar oscillations (not shown). Oscillations in power output are also visible at the other two wind farms (although those oscillations are not as regular) because mountain wake effects might play a role at those farms as well.

\section{Discussion}

The previous sections discussed a mountain wave event in the Columbia River basin through simulations and observations. The signature of these waves was apparent in nacelle wind speeds and power observations of a wind farm in the area. In this section, we relate our findings to practical aspects in forecasting and operations.

During the event of 24 September 2016, oscillations in power caused by mountain waves are at such a critical point in the power curve (region 2, or the "steep part") that small oscillations about the overall mean flow can make all the difference between full-rated power or approximately $1 \mathrm{MW}$ of power at any given time. In this particular case, the oscillations of a few meters per second caused by the mountain waves have dramatic effects on power production. Even after aggregating the power output from all turbines, the power still fluctuates approximately $25 \mathrm{MW}$ from mountain waves at the wind farm. For this wind plant, this is equivalent to production from approximately 10 turbines being added or lost during the presence of the wave's crests and troughs (assuming all turbines are on), given that one turbine could produce approximately $2.3 \mathrm{MW}$. About $11 \%$ of the total wind farm output is being influenced by the presence of mountain waves, which is considered significant according to the empirical threshold used in the industry that more than $10 \%$ in fluctuations (or 20 MW) is significant.

Discerning signals from mountain waves from signals caused by other phenomena in the atmosphere can be chal- 


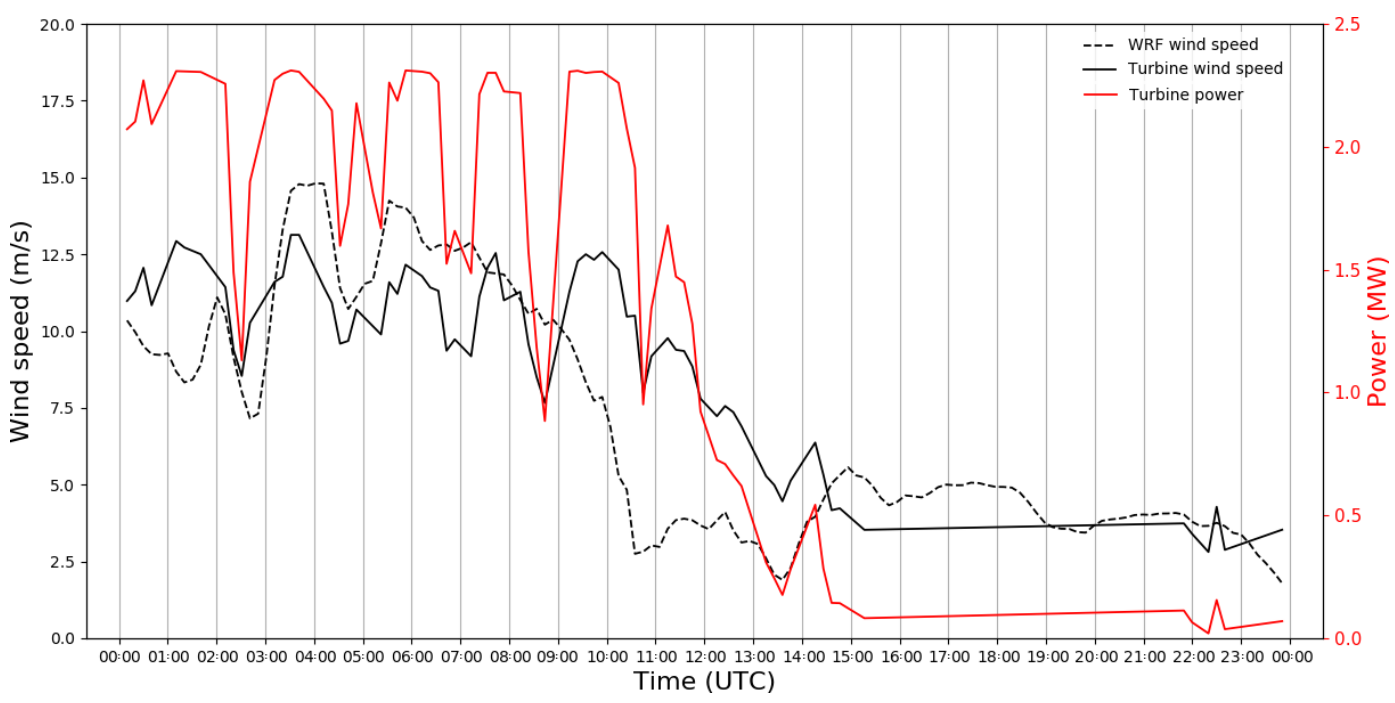

Figure 12. Time series of simulated $80 \mathrm{~m}$ wind speed from WRF (dashed line), observed power output from one turbine near the middle of the wind farm (red), and wind speed measurements from that turbine (black solid line).

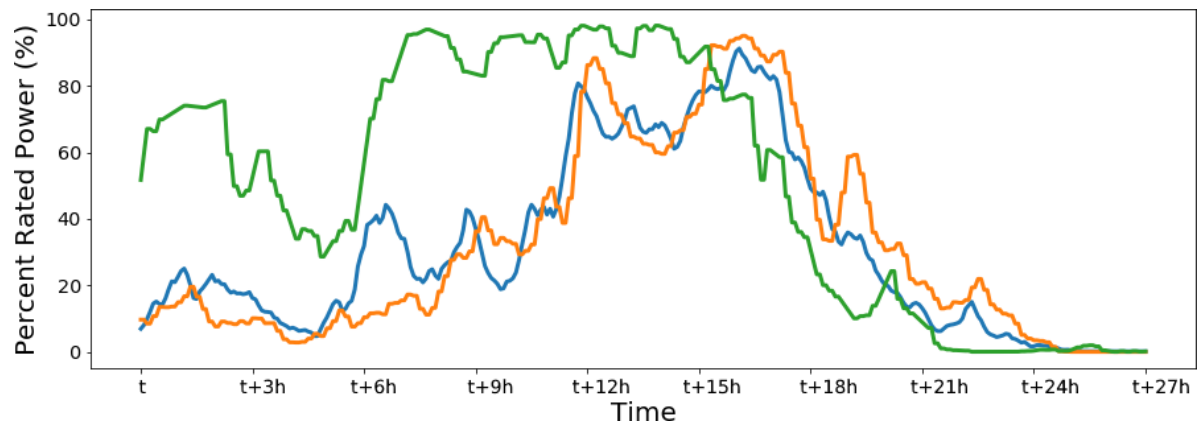

Figure 13. Time series of total power output of the wind farm used in this study (green) and two other wind farms in the area (orange and blue). The values on the $x$ axis show time at $3 \mathrm{~h}$ intervals.

lenging. For example, mountain waves and wakes often occur concurrently, and the signals in time series of wind speed when analyzing observations at a single site or wind turbines can be difficult to distinguish. Mountain wakes impacting wind turbines in the Columbia River basin are mostly created by Mt. Hood. To the north of a Mt. Hood wake are the Columbia River Gorge gap-flow westerlies, and to the south are geostrophic southwesterlies that can sometimes mix down to the southernmost and highest-elevation turbines in the area. The instability of the mountain wake edge leads to much volatility, and it is common for entire wind power plants to go back and forth between being in the lull and being at full power. Concurrently occurring mountain wakes and waves can lead to high-volatility periods where forecasts range from zero to full power. Power data might also include various aspects, such as curtailments and turbine wakes. During our case study, the wind farm was not curtailed. Additionally, analyses of the simulated spatial wind field, as well as cloud cover by GOES satellite data (not shown), indicate that the mountain waves appeared to shift around without sys- tematic upstream or downstream propagation on 24 September 2016. This points to nonlinear interactions between different waves and that the dominant dynamics are nonlinear (Nance and Durran, 1997, 1998, Part II). Nonetheless, mountain waves showed up in periodic signals in wind speed and power (Figs. 9-12).

We analyzed the wavelengths of the mountain waves; they ranged from 8 to $10 \mathrm{~km}$ in the two case studies (24 September and 11 November 2016; Wilczak et al., 2019) and were well captured by the numerical simulations. Future studies will include further quantification of wavelengths and whether both shorter and longer wavelengths appear simultaneously in a wind farm region. During periods with shorter wavelengths, only parts of a wind plant will experience low wind speeds, while other parts will be exposed to stronger winds, which can result in canceling effects so that power output is minimally affected. During these cases, accurate mountain wave and wavelength forecasts are important for wind plant operators to save on balancing costs. On the contrary, if wavelengths are long, entire regions can oscillate between 
near-full and near-zero power, and, in particular situations, a lull over an entire region can occur, encompassing multiple wind farms. Similarly, problems arise if wind farms are spaced apart such that two wind plants happen to be in lulls while high wind speeds occur between them. Knowing when to trust model wavelength forecasts will be the subject of future studies. In terms of speed of wave propagation, our research has shown that not all mountain waves exhibit the same speed. In the case of 24 September 2016, the simulated waves move with a speed of approximately $1.5 \mathrm{~m} \mathrm{~s}^{-1}$ (Sect. 3.2.3); in the case of 11 November 2016 (Wilczak et al., 2019), the simulated waves move at $2 \mathrm{~m} \mathrm{~s}^{-1}$ (computed the same way as in Sect. 3.2.3). This seems to contradict our findings from analyzing GOES satellite data, which showed no systematic propagation. Both extended wavelength and wave speed analyses are the subjects of future work.

From an operational perspective, using high-resolution forecasts that can resolve mountain waves is crucial to predict power output at a particular wind farm. The grid spacing of the simulations should be fine enough for a forecaster to recognize mountain waves. For example, even though waves are reflected in a wind field simulated on a $3 \mathrm{~km}$ grid, they might not be recognized as such because the waves are too wide or missing clear distinctions between high and low wind speeds that are the result of wave crests and troughs. Sharp gradients between near-zero and near-full power need to be recognizable when a forecaster looks at model simulations. Even though it is impossible to nail down the exact location of the wave crests and troughs, speed of propagation, magnitudes of wind speeds, or wavelength, the forecaster can recognize the risk for mountain waves and associated large drops or surges in power. Additionally, if high-resolution forecasts are misinterpreted (i.e., the position of wave crests and troughs are overly trusted), they have the potential to degrade a forecast. For a forecaster, it is key to be informed about the occurrence of mountain waves in order to act (e.g., assign more balancing reserves for volatility to make sure a wide range of possible production is covered). At forecasts near full power, a mountain wave event can be indicative of reductions of power. In any event, mountain wave forecasts should not be used as deterministic solutions.

\section{Summary and conclusions}

We have shown that mountain waves can occur frequently in areas of complex terrain and can be modeled with mesoscale models as was confirmed by observations. Mountain waves can impact wind turbine and wind farm power output and, therefore, should be considered in complex terrain when designing, building, and forecasting for wind farms. Mountain waves impact the quantity of the wind resource and the quality by impacting temporal and spatial variability.

We suggest that forecasters be informed when mountain waves occur and, therefore, be informed about wind variabil- ity in order to act accordingly (e.g., when setting day-ahead positions for balancing reserves and schedules). Even though the nuances of wavelength, wave propagation, or exact location are not easy to identify or simulate (because they depend on the upstream wind speed and direction as well as the vertical stability profile), being aware when mountain waves are forecast is key in operational wind energy forecasting in complex terrain. Information about the occurrence of mountain waves adds value by communicating the risk and probability of variability in power output, which helps planning for possible extreme situations. Depending on the mountain wave event and the size and shape of wind plants, effects tend to cancel out over large areas. For this to be true, wind farms should be laid out such that the windward and leeward portions are equally exposed to the mountain wave pattern. Determining the best size and orientation of wind plants to minimize mountain wave effects would be a recommendation for future studies.

Future studies should also include analyses of aggregates over larger regions to see wave patterns through wind plants as well as interactions with mountain wakes. Often, particular regions have their own peculiarities, which might also be a function of turbine age and kind, location, or elevation. 


\section{Appendix A}

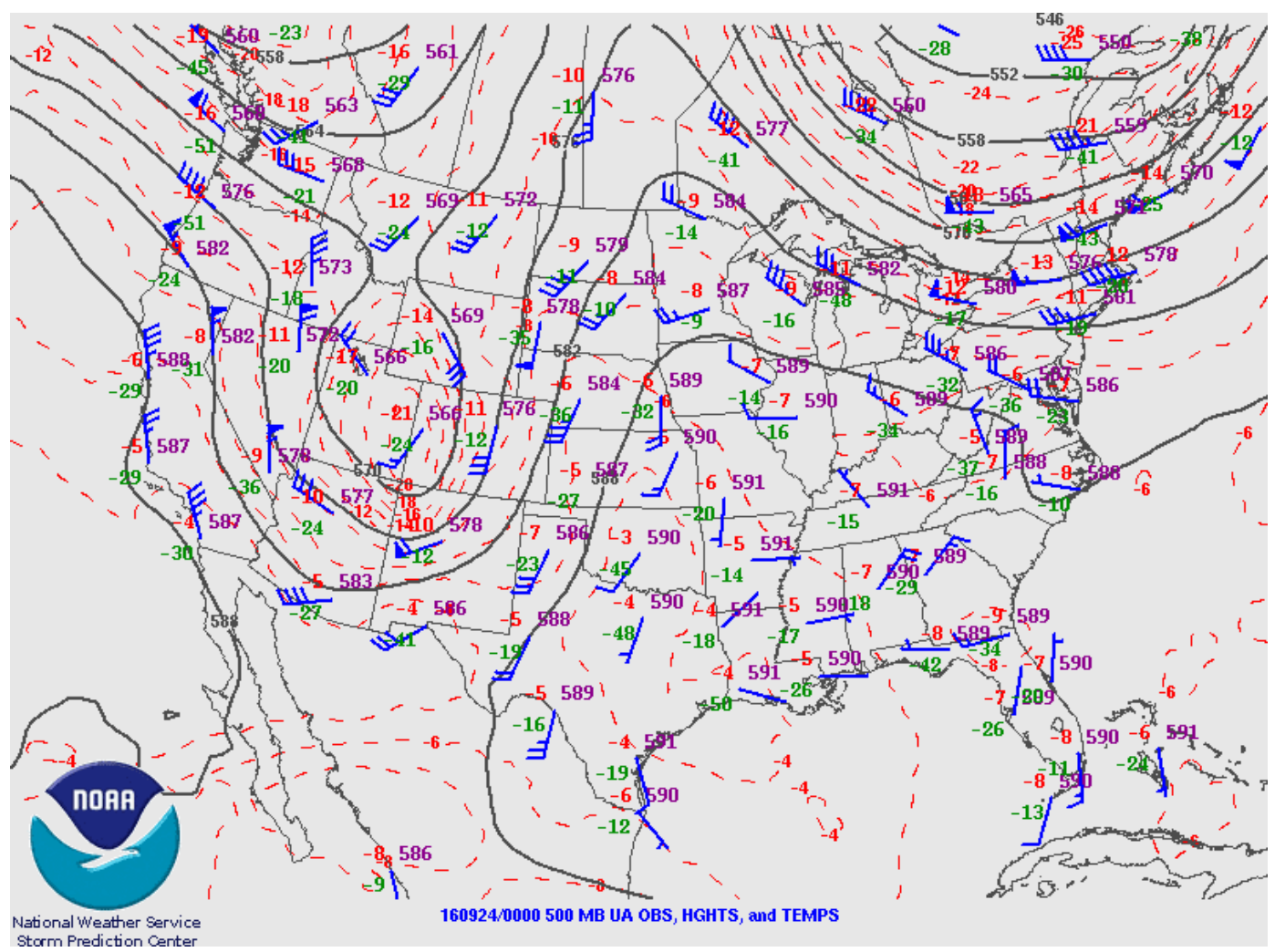

Figure A1. Pressure at $500 \mathrm{hPa}$ (black lines), temperature (dashed red), wind barbs (blue), temperature (red numbers), and dew point (green numbers). Source: National Weather Service. 
Code and data availability. The measurement data that support the findings of this study are openly available in the Data Archive and Portal (DAP), available at https://a2e. energy.gov/data (U.S. Department of Energy, 2020) (specifically https://doi.org/10.21947/1349278, Atmosphere to Electrons, 2017a; https://doi.org/10.21947/1409334, Atmosphere to Electrons, 2017b). The DAP establishes a sustained data management structure with protocols and access to assure massive datasets resulting from DOE A2e (Atmosphere to Electrons) efforts will have the quality needed for scientific discovery and portals required to make data available to a broad stakeholder group. The WRF simulations and code are available from the lead author upon request. Data from wind farms are proprietary and were used under license for this study and are therefore not publicly available.

Supplement. The supplement related to this article is available online at: https://doi.org/10.5194/wes-6-45-2021-supplement.

Author contributions. CD prepared the paper with contributions from all co-authors. CD conceptualized, administered, and supervised the project; provided formal analysis, validation, and visualization; investigated the data; acquired resources; used analysis software; and took part in the writing, reviewing, and editing of the paper. RW conceptualized the project; provided formal analysis, data curation, validation, and visualization; investigated the data; acquired resources; used analysis software; and took part in the writing, reviewing, and editing of the paper. GX provided formal analysis, data curation, validation, and visualization; investigated the data; acquired resources; used analysis software; and took part in the writing of the paper. YP provided formal analysis, data curation, validation, and visualization; investigated the data; acquired resources; used analysis software; and took part in the writing of the paper. DC provided formal analysis, data curation, and visualization; investigated the data; acquired resources; used analysis software; and took part in the writing of the paper. JL conceptualized the project; provided formal analysis; and took part in the writing, reviewing, and editing of the paper. JS conceptualized the project and took part in the writing of the paper. GW conceptualized the project and took part in the writing of the paper. JW conceptualized the project; provided formal analysis; and took part in the writing, reviewing, and editing of the paper. LB conceptualized the project.

Competing interests. The authors declare that they have no conflict of interest.

Acknowledgements. The authors thank the WFIP2 experiment participants who aided in the deployment and the collection of remote sensing data and our colleagues who monitored, qualitycontrolled, and provided data to the Data Archive Portal (DAP). Special thanks go to Joe Cline (DOE), Melinda Marquis (NOAA), and Jim McCaa (Vaisala) for their effort to propose, design, and lead the WFIP2. The research was performed using computational resources sponsored by the Department of Energy's Office of Energy Efficiency \& Renewable Energy and located at the National Renew- able Energy Laboratory. Lastly, we thank two anonymous reviewers for their comments, which helped improve the paper.

This work was authored in part by the National Renewable Energy Laboratory, operated by Alliance for Sustainable Energy, LLC, for the U.S. Department of Energy (DOE) under contract no. DEAC36-08GO28308. Funding was provided by the U.S. Department of Energy Office of Energy Efficiency \& Renewable Energy Wind Energy Technologies Office. This work was partially supported by the National Oceanic and Atmospheric Administration (NOAA) Atmospheric Science for Renewable Energy (ASRE) program. The views expressed in the article do not necessarily represent the views of the DOE or the U.S. Government. The U.S. Government retains and the publisher, by accepting the article for publication, acknowledges that the U.S. Government retains a nonexclusive, paid-up, irrevocable, worldwide license to publish or reproduce the published form of this work, or allow others to do so, for U.S. Government purposes. A portion of the research was performed using computational resources sponsored by the Department of Energy's Office of Energy Efficiency and Renewable Energy and located at the National Renewable Energy Laboratory.

Financial support. This research has been supported by the U.S. Department of Energy Office of Energy Efficiency \& Renewable Energy (grant no. DE-AC36-08GO28308).

Review statement. This paper was edited by Andrea Hahmann and reviewed by Rogier Floors and one anonymous referee.

\section{References}

Aitken, M. L., Rhodes, M. E., and Lundquist, J. K.: Performance of a Wind-Profiling Lidar in the Region of Wind Turbine Rotor Disks, J. Atmos. Ocean. Tech., 29, 347-355, https://doi.org/10.1175/JTECH-D-11-00033.1, 2012.

Atmosphere to Electrons (A2e): wfip2/sodar.z08.b0, Maintained by A2e Data Archive and Portal for U.S. Department of Energy, Office of Energy Efficiency and Renewable Energy, https://doi.org/10.21947/1349278, 2017a.

Atmosphere to Electrons (A2e): wfip2/sodar.z06.b0, Maintained by A2e Data Archive and Portal for U.S. Department of Energy, Office of Energy Efficiency and Renewable Energy, https://doi.org/10.21947/1409334, 2017b.

AWEA Data Services: U.S. Wind Industry Fourth Quarter 2017 Market Report, https://doi.org/10.1002/ejoc.201200111, 2020.

Banta, R. M., Pichugina, Y. L., Brewer, W. A., Choukulkar, A., Lantz, K. O., Olson, J. B., Kenyon, J., Fernando, H. J., Krishnamurthy, R., Stoelinga, M. J., Sharp, J., Darby, L. S., Turner, D. D., Baidar, S., and Sandberg, S. P.: Characterizing NWP Model Errors Using Doppler-Lidar Measurements of Recurrent Regional Diurnal Flows: Marine-Air Intrusions into the Columbia River Basin, Mon. Weather Rev., 148, 929-953, https://doi.org/10.1175/MWR-D-19-0188.1, 2020.

Bianco, L., Djalalova, I. V., Wilczak, J. M., Olson, J. B., Kenyon, J. S., Choukulkar, A., Berg, L. K., Fernando, H. J. S., Grimit, E. P., Krishnamurthy, R., Lundquist, J. K., Muradyan, P., Pekour, M., Pichugina, Y., Stoelinga, M. T., and Turner, D. D.: Im- 
pact of model improvements on $80 \mathrm{~m}$ wind speeds during the second Wind Forecast Improvement Project (WFIP2), Geosci. Model Dev., 12, 4803-4821, https://doi.org/10.5194/gmd-124803-2019, 2019.

Bodini, N., Lundquist, J. K., Krishnamurthy, R., Pekour, M., Berg, L. K., and Choukulkar, A.: Spatial and temporal variability of turbulence dissipation rate in complex terrain, Atmos. Chem. Phys., 19, 4367-4382, https://doi.org/10.5194/acp19-4367-2019, 2019.

Bougeault, P., Binder, P., Buzzi, A., Dirks, R., Houze, R., Kuettner, J., Smith, R. B., Steinacker, R., and Volkert, H.: The MAP Special Observing Period, B. Am. Meteorol. Soc., 82, 433-462, https://doi.org/10.1175/15200477(2001)082<0433:TMSOP>2.3.CO;2, 2001.

Dee, D. P., Uppala, S. M., Simmons, A. J., Berrisford, P., Poli, P., Kobayashi, S., Andrae, U., Balmaseda, M. A., Balsamo, G., Bauer, P., Bechtold, P., Beljaars, A. C. M., van de Berg, L., Bidlot, J., Bormann, N., Delsol, C., Dragani, R., Fuentes, M., Geer, A. J., Haimberger, L., Healy, S. B., Hersbach, H., Hólm, E. V., Isaksen, L., Kållberg, P., Köhler, M., Matricardi, M., McNally, A. P., Monge-Sanz, B. M., Morcrette, J.-J., Park, B.-K., Peubey, C., de Rosnay, P., Tavolato, C., Thépaut, J.-N., and Vitart, F.: The ERA-Interim reanalysis: configuration and performance of the data assimilation system, Q. J. Roy. Meteor. Soc., 137, 553-597, https://doi.org/10.1002/qj.828, 2011.

Doyle, J. D. and Durran, D. R.: The Dynamics of Mountain-Wave-Induced Rotors, J. Atmos. Sci., $\quad 59, \quad 186-201, \quad$ https://doi.org/10.1175/15200469(2002)059<0186:TDOMWI>2.0.CO;2, 2002.

Durran, D. R.: Mountain Waves and Downslope Winds, in: Atmospheric Processes over Complex Terrain, Meteorological Monographs, edited by: Blumen, W., 23. American Meteorological Society, Boston, MA, https://doi.org/10.1007/978-1-935704-256_4, 1990.

Durran, D. R.: Lee waves and mountain waves. Encyclopedia of Atmospheric Sciences, Academic Press, 1161-1169, ISBN 9780122270901, https://doi.org/10.1016/B0-12-2270908/00202-5, 2003.

Durran, D. R.: Mountain Meteorology. Lee Waves and Mountain Waves, Encyclopedia of Atmospheric Sciences (Second Edition), Academic Press, 95-102, ISBN 9780123822253, https://doi.org/10.1016/B978-0-12-382225-3.00202-4, 2015.

Fritts, D. C.: Gravity Waves Overview, Encyclopedia of Atmospheric Sciences (Second Edition), Academic Press, 141152, ISBN 9780123822253, https://doi.org/10.1016/B978-0-12382225-3.00234-6, 2015.

Global Wind Energy Council: Global wind statistics 2017, available at: http://gwec.net/wp-content/uploads/vip/GWEC_ PRstats2017_EN-003_FINAL.pdf (last access: 23 December 2020), 2018.

Grubišić, V. and Billings, B. J.: The Intense Lee-Wave Rotor Event of Sierra Rotors IOP 8, J. Atmos. Sci., 64, 4178-4201, https://doi.org/10.1175/2006JAS2008.1, 2007.

Haupt, S. E., Kotamarthi, R., Feng, Y., Mirocha, J. D., Koo, E., Linn, R., Kosovic, B., Brown, B., Anderson, A., Churchfield, M. J., Draxl, C., Quon, E., Shaw, W., Berg, L., Rai, R., and Ennis, B. L: Second year report of the atmosphere to electrons mesoscale to microscale coupling project: nonstationary modelling techniques and assessment, Technical Report PNNL-26267, Pacific Northwest National Laboratory, Richland, WA, USA, 2017.

Klemp, J. B. and Lilly, D. K.: Numerical Simulation of Hydrostatic Mountain Waves, J. Atmos. Sci., 35, 78-107, https://doi.org/10.1175/15200469(1978)035<0078:NSOHMW>2.0.CO;2, 1978.

Lindsay, C. V.: Mountain Waves in the Appalachians, Mon. Weather Rev., 90, 271-276, https://doi.org/10.1175/15200493(1962)090<0271:MWITA>2.0.CO;2, 1962.

Mahalov, A., Moustaoui, M., and Grubišić, V.: A numerical study of mountain waves in the upper troposphere and lower stratosphere, Atmos. Chem. Phys., 11, 5123-5139, https://doi.org/10.5194/acp-11-5123-2011, 2011.

Mastaler, R. A. and Renno, N. O.: The Froude number as a predictor of mountain lee wave phenomenon, Technical Soaring, 29, 78$88,2005$.

Miglietta, M. M., Zecchetto, S., and De Biasio, F.: A comparison of WRF model simulations with SAR wind data in two case studies of orographic lee waves over the Eastern Mediterranean Sea, Atmos. Res., 120-121, 127-146, https://doi.org/10.1016/j.atmosres.2012.08.009, 2013.

Nakanishi, M. and Niino, H.: Development of an improved turbulence closure model for the atmospheric boundary layer, J. Meteorol. Soc. Jpn. II, 87, 895-912, https://doi.org/10.2151/jmsj.87.895, 2009.

Nance, L. B. and Durran, D. R.: A Modeling Study of Nonstationary Trapped Mountain Lee Waves. Part I: Mean-Flow Variability, J. Atmos. Sci., 54, 2275-2291, https://doi.org/10.1175/15200469(1997)054<2275:AMSONT>2.0.CO;2, 1997.

Nance, L. B. and Durran, D. R.: A Modeling Study of Nonstationary Trapped Mountain Lee Waves. Part II: Nonlinearity, J. Atmos. Sci., 55, 1429-1445, https://doi.org/10.1175/15200469(1998)055<1429:AMSONT>2.0.CO;2, 1998.

Nappo, C. J.: Mountain Waves, International Geophysics, Academic Press, Cambridge, Massachusetts, US, 102, 5785, ISBN 9780123852236, https://doi.org/10.1016/B978-0-12385223-6.00003-3, 2012.

Olson, J., Kenyon, J. Djalalova, I. Bianco, L., Turner, D., Pichugina, Y., Choukulkar, A., Toy, M., Brown, J. M., Angevine, W., Akish, E., Bao, J.-W., Jimenez, P., Kosovic, B., Lundquist, K., Draxl, C., Lundquist, J. K., McCaa, J., McCaffrey, K., Lantz, K., Long, C., Wilczak, J., Banta, R., Marquis, M., Redfern, S., Berg, L. K., Shaw, W., and Cline, J.: Improving Wind Energy Forecasting through Numerical Weather Prediction Model Development, B. Am. Meteorol. Soc., 100, 2201-2220, https://doi.org/10.1175/BAMS-D-18-0040.1, 2019.

Pichugina, Y. L., Banta, R. M., Bonin, T., Brewer, W. A., Choukulkar, A., McCarty, B. J., Baidar, S., Draxl, C., Fernando, H. J., Kenyon, J., Krishnamurthy, R., Marquis, M., Olson, J., Sharp, J., and Stoelinga, M.: Spatial Variability of Winds and HRRR-NCEP Model Error Statistics at Three DopplerLidar Sites in the Wind-Energy Generation Region of the Columbia River Basin, J. Appl. Meteorol. Clim., 58, 1633-1656, https://doi.org/10.1175/JAMC-D-18-0244.1, 2019.

Pichugina, Y., Banta, R., Brewer, W. A., Bianco, L., Draxl, C., Kenyon, J., Lundquist, J. K., Olson, J., Turner, D. D., Wharton, S., Wilczak, J., Baidar, S., Berg, L., Fernando, H. J. S., McCarty, B., Rai, R., Roberts, B., Sharp, J., Shaw, W., Stoelinga, M., and Worsnop, R.: Evaluating the WFIP2 updates to the 
HRRR model using scanning Doppler lidar measurements in the complex terrain of the Columbia River Basin, JRSE, 12, https://doi.org/10.1063/5.0009138, 2020.

Rasheed, A., Süld, J. K., and Kvamsdal, T.: A Multiscale Wind and Power Forecast System for Wind Farms, Enrgy. Proced., 53, 290-299, https://doi.org/10.1016/j.egypro.2014.07.238, 2014.

Reichmann, H.: Cross-Country Soaring (Streckensegelflug), Thomson Publications, 150 pp., ISBN-13 978-1883813017, 1978.

Reinecke, P. A. and Durran, D. R.: Estimating Topographic Blocking Using a Froude Number When the Static Stability Is Nonuniform, J. Atmos. Sci., 65, 1035-1048, https://doi.org/10.1175/2007JAS2100.1, 2008

Rhodes, M. E. and Lundquist, J. K.: The Effect of Wind-Turbine Wakes on Summertime US Midwest Atmospheric Wind Profiles as Observed with Ground-Based Doppler Lidar, Bound-Lay. Meteorol., 149, 85-103, https://doi.org/10.1007/s10546-013-9834$\mathrm{x}, 2013$.

Scorer, R. S.: Theory of waves in the lee of mountains, Q. J. Roy. Meteor. Soc., 75, 41-56, https://doi.org/10.1002/qj.49707532308, 1949.

Shaw, W. J., Berg, L. K., Cline, J., Draxl, C., Djalalova, I., Grimit, E. P., Lundquist, J. K., Marquis, M., McCaa, J., Olson, J. B., Sivaraman, C., Sharp, J., and Wilczak, J. M.: The Second Wind Forecast Improvement Project (WFIP 2): General Overview, B. Am. Meteorol. Soc., 100, 1687-1699, https://doi.org/10.1175/BAMSD-18-0036.1, 2019.

Skamarock, W. C., Klemp, J. B., Dudhia, J., Gill, D. O., Barker, D., Duda, M. G., Huang, X. Y., Wang, W., and Powers, J. G.: A Description of the Advanced Research WRF Version 3 (No. NCAR/TN-475+STR), University Corporation for Atmospheric Research, https://doi.org/10.5065/D68S4MVH, 2008.

Smith, R., Doyle, J. D., Jiang, Q., and Smith, S.: Alpine gravity waves: Lessons from MAP regarding mountain wave generation and breaking, Q. J. Roy. Meteor. Soc., 133, 917-936, https://doi.org/10.1002/qj.103, 2007.

Smith, S. A.: Observations and simulations of the 8 November 1999 MAP mountain wave case, Q. J. Roy. Meteor. Soc., 130, 13051325, https://doi.org/10.1256/qj.03.112, 2004.
Smith, S. A. and Broad, A. S.: Horizontal and temporal variability of mountain waves over Mont Blanc, Q. J. Roy. Meteor. Soc., 129, 2195-2216, https://doi.org/10.1256/qj.02.148, 2003.

U.S. Department of Energy: Wind Vision: A New Era for wind power in the United States, available at: http://www. energy.gov/sites/prod/files/WindVision_Reportfinal.pdf, last access: 17 March 2020.

U.S. Department of Energy: Data Archive and Portal, available at: https://a2e.energy.gov/data, last access: 23 December 2020.

Vosper, S. B., Wells, H., Sinclair, J. A., and Sheridan, P. F.: A climatology of lee waves over the UK derived from model forecasts, Royal Met. Soc., 20, 466-481, https://doi.org/10.1002/met.1311, 2012.

Wells, H., Vosper, S. B., Webster, S., Ross, A. N., and Brown, A. R.: The impact of mountain wakes on the drag exerted on downstream mountains, Q. J. Roy. Meteor. Soc., 134, 677-687, https://doi.org/10.1002/qj.242, 2008.

Wikipedia: Cascade Range, available at: https://en.wikipedia.org/ wiki/Cascade_Range, last access: 23 December 2020.

Wilczak, J. M., Stoelinga, M., Berg, L. K., Sharp, J., Draxl, C., McCaffrey, K., Banta, R. M., Bianco, L., Djalalova, I., Lundquist, J. K., Muradyan, P., Choukulkar, A., Leo, L., Bonin, T., Pichugina, Y., Eckman, R., Long, C. N., Lantz, K., Worsnop, R. P., Bickford, J., Bodini, N., Chand, D., Clifton, A., Cline, J., Cook, D. R., Fernando, H. J., Friedrich, K., Krishnamurthy, R., Marquis, M., McCaa, J., Olson, J. B., Otarola-Bustos, S., Scott, G., Shaw, W. J., Wharton, S., and White, A. B.: The Second Wind Forecast Improvement Project (WFIP 2): Observational Field Campaign, B. Am. Meteorol. Soc., 100, 1701-1723, https://doi.org/10.1175/BAMS-D-18-0035.1, 2019.

Xia, G., Draxl, C., Raghavendra, A., and Lundquist, J. K.: Validating simulated mountain wave impacts on hub-height wind speed using SoDAR observations, Renew. Energ, 163, 2220 2230, https://doi.org/10.1016/j.renene.2020.10.127, 2020. 